\title{
Broad-Spectrum Resistance to Crown Rust, Puccinia coronata f. sp. avenae, in Accessions of the Tetraploid Slender Oat, Avena barbata
}

\author{
M. L. Carson, United States Department of Agriculture-Agricultural Research Service, Cereal Disease Lab, Univer- \\ sity of Minnesota, St. Paul 55108
}

\begin{abstract}
Carson, M. L. 2009. Broad-spectrum resistance to crown rust, Puccinia coronata f. sp. avenae, in accessions of the tetraploid slender oat, Avena barbata. Plant Dis. 93:363-366.

The use of race-specific seedling genes for resistance has been the primary means of controlling crown rust of oat (Puccinia coronata). As resistance genes from hexaploid cultivated oat, Avena sativa and, later, the wild hexaploid animated oat, A. sterilis, were deployed in oat cultivars, corresponding virulence in the crown rust population increased rapidly, such that the effective lifespan of a resistant cultivar in the United States is now 5 years or less. Introgression of resistance genes from diploid and tetraploid Avena spp. into hexaploid oat has been difficult due to differences in ploidy levels and the lack of homology of chromosomes between the two species. The wild tetraploid slender oat, A. barbata, has been a source of powdery mildew and stem rust resistance in cultivated oat but has largely been unexploited for crown rust resistance. In total, 359 accessions of $A$. barbata from the National Small Grains Collection were evaluated in seedling greenhouse tests. Of these accessions, $39 \%$ were at least moderately resistant when inoculated with a crown rust race with low virulence (DBBC). When tested further with a highly diverse bulk inoculum from the 2006 and 2007 St. Paul buckthorn nursery, 48 accessions (approximately 13\%) were resistant. Many of these accessions were heterogeneous in reaction, but two accessions (PI320588 from Israel and PI337893 from Italy) were highly resistant (immune) and two others (PI337886 from Italy and PI367293 from Spain) consistently produced resistant reactions (chlorotic flecks) in all tests. Resistant accessions were found from throughout much of the natural range of A. barbata. Crosses of some of the better accessions have been made to cultivated oat.
\end{abstract}

Crown rust, caused by Puccinia coronata Corda f. sp. avenae P. Syd. \& Syd., is the most damaging fungal disease of domesticated oat, Avena sativa $\mathrm{L}$., in the world (15). The disease is most damaging when heavy dews coincide with moderate temperatures during the growing season. In the United States, there are two major oatproduction areas. Winter oat, sown in the fall and harvested in the spring, is grown in parts of the southern United States, often as a dual purpose (forage and grain) crop. Spring oat, sown in the early spring and harvested midsummer, is grown in the upper Midwest, mainly as a grain crop. In the winter-oat region, $P$. coronata successfully overwinters and crown rust epidemics can be severe because multiple infection cycles with urediniospores can occur over the long growing season. In the spring-oat region, the alternate host of $P$. coronata, common buckthorn (Rhamnus cathartica L.), is a widespread, pervasive,

Corresponding author: M. L. Carson

E-mail: mcarson@umn.edu

Accepted for publication 7 December 2008.

doi:10.1094/PDIS-93-4-0363

This article is in the public domain and not copyrightable. It may be freely reprinted with customary crediting of the source. The American Phytopathological Society, 2009. noxious weed in wooded areas and shelter belts adjacent to oat fields. Aeciospores from buckthorn as well as urediniospores from southern winter-oat production areas serve as abundant initial sources of inoculum in the spring-oat region.

Host resistance has been the primary means of controlling losses to crown rust in cultivated oat. The use of race-specific seedling genes for resistance to crown rust has a long history in the United States. Initially, cultivated hexaploid oat, $A$. sativa, was used as a source of crown rust resistance $(P c)$ genes. As cultivars with these genes were deployed, they rapidly succumbed to new virulent races of $P$. coronata. Virulence to $P c$ genes derived from $A$. sativa is now nearly fixed in the North American population of $P$. coronata. Subsequently, oat breeders turned to the wild hexaploid animated oat, $A$. sterilis, as a source of new $P c$ genes, but virulence to many of these genes was already present in the $P$. coronata population or increased rapidly as they were deployed in new cultivars. Virulence to all the reported $P c$ genes from A. sterilis is present in the U.S. crown rust population and the virulence complexity has continued to increase unabated (3). More recent efforts at finding new, effective $P c$ genes have centered on diploid or tetraploid Avena spp.. Crown rust resistance in the diploid black oat, $A$. strigosa, has been known and documented for quite some time but introgression of resistance into hexaploid oat is difficult due to differences in ploidy levels and the lack of homology of chromosomes between the two species $(2,8,14)$. Cv. Leggett, recently released by the AAFC Winnipeg program, contains $P c 94$ from the A. strigosa accession RL1697 (2). An effective crown rust resistance gene $(P c 91)$ from the tetraploid species, A. magna CI 8330 , was successfully transferred via the synthetic hexaploid Amagalon into oat cv. Hi-Fi, released by North Dakota State University in 2001 (12).

A. barbata Pott ex Link is a wild tetraploid $(2 n=28)$ species that is widely distributed in the Mediterranean region, North Africa, the Middle East, South Asia, and much of Europe (9). It has also been introduced to Australia and the Americas. It is adapted to a range of natural and artificial habitats ranging from sea level to the snow line. In the United States, it is considered a restricted species because it is listed as a noxious weed by the state of Missouri and is considered a moderately invasive species of natural areas in California.

Genes for resistance to powdery mildew $(E g-4)$ and stem rust $(P g-16)$ have been successfully transferred from $A$. barbata into cultivated hexaploid oat $(1,10,16)$. Resistance to crown rust in A. barbata has been reported in collections from Israel, Turkey, Portugal, and Australia; however, testing was done with a limited number of collections and races of $P$. coronata $(5,6,11)$. In some cases, collections were resistant as seedlings but susceptible as adult plants and, in at least one instance, were susceptible as seedlings but resistant as adults (6).

\section{MATERIALS AND METHODS}

Available seed of $A$. barbata and $A$. barbata subsp. barbata was obtained from the United States Department of Agriculture (USDA) Agricultural Research Service National Small Grains Germplasm Collection in Aberdeen, ID. In all, 402 accessions were planted in vermiculite in $7-\mathrm{cm}^{2}$ pots with 10 to 20 seeds of each of four accessions planted in each corner of the pot. In every sixth pot, 10 to 15 seeds of the susceptible oat cv. Marvellous was planted in one corner to serve as a check for uniformity and viability of inoculum. Seven days after planting, primary leaves of seedlings were inoculated with a min- 
eral oil suspension of fresh urediniospores of a single-pustule-derived isolate of $P$. coronata $\mathrm{f}$. sp. avenae with virulence on only 2 of 31 differential cultivars (06MN097), designated race DBBC according to the nomenclature of Chong et al (4). Inoculated plants were placed in a dew chamber overnight and moved to a greenhouse bench. Crown rust reactions were recorded 12 to 14 days after inoculation. A crown rust reaction of moderately large to large pustules with little or no chlorosis was scored as susceptible, those with moderately large pustules surrounded with extensive chlorosis were scored as moderately susceptible, those with small pustules surrounded by chlorosis or necrosis were scored as moderately resistant, those with chlorotic or necrotic flecks were scored as resistant, and those with no visible reaction were scored as highly resistant.

Seedlings of accessions of $A$. barbata that were scored at least moderately resistant in the initial test with race DBBC were fertilized with a solution of water-soluble fertilizer (Plantex 20-20-20, NPK; Plant Products Co. Ltd., Brampton, Ontario, Canada) and newly emerged leaves reinoculated as described above with a bulk population of $P$. coronata $\mathrm{f}$. sp. avenae urediniospores collected in 2006 from the buckthorn nursery in St. Paul. The buckthorn and oat nursery at St. Paul, MN has been in existence since 1953 and supports an extremely diverse, sexually recombining population of $P$. coronata. In a given year, virulence to almost every described $P c$ gene in Avena spp. is detected in this population (Table 1). Crown rust reactions to the bulk population were recorded as described above.

Seed of accessions of $A$. barbata that were scored moderately resistant or better when tested with the 2006 bulk population of $P$. coronata $\mathrm{f}$. sp. avenae were planted and inoculated with a bulk population of $P$. coronata f. sp. avenae from the 2007 St. Paul buckthorn nursery and scored as de-

Table 1. Crown rust severities and reaction types on flag leaves of adult plants of oat differential lines in the St. Paul buckthorn nursery, 2006-08, and reactions of seedlings of those differentials to bulk urediniospore populations of Puccinia coronata from the buckthorn nursery (2007 and 2008) in greenhouse tests ${ }^{\mathrm{a}}$

\begin{tabular}{|c|c|c|c|c|c|}
\hline \multirow[b]{2}{*}{ Differential } & \multicolumn{2}{|c|}{ Greenhouse } & \multicolumn{3}{|c|}{ Nursery } \\
\hline & 2007Bulk & 2008Bulk & 2006 & 2007 & 2008 \\
\hline Pc14 & $\mathrm{S}$ & $\mathrm{S}$ & $80 \mathrm{~S}$ & $80 \mathrm{~S}$ & $20 \mathrm{~S}$ \\
\hline Pc35 & $\mathrm{S}$ & $\mathrm{S}$ & $80 \mathrm{~S}$ & $80 \mathrm{~S}$ & $30 \mathrm{~S}$ \\
\hline Pc36 & $\mathrm{S}$ & $\mathrm{S}$ & $80 \mathrm{~S}$ & $80 \mathrm{~S}$ & $80 \mathrm{~S}$ \\
\hline Pc38 & $\mathrm{S}$ & $\mathrm{S}$ & $80 \mathrm{~S}$ & Dead & $40 \mathrm{~S}$ \\
\hline Pc39 & $\mathrm{S}$ & $\mathrm{S}$ & $80 \mathrm{~S}$ & Dead & $50 \mathrm{~S}$ \\
\hline Pc40 & $\mathrm{S}$ & $\mathrm{S}$ & $80 \mathrm{~S}$ & $80 \mathrm{~S}$ & $20 \mathrm{~S}$ \\
\hline Pc45 & $\mathrm{S}$ & $\mathrm{S}$ & $20 \mathrm{MS}$ & $80 \mathrm{~S}$ & $10 \mathrm{MR}$ \\
\hline Pc46 & $\mathrm{S}$ & $\mathrm{S}$ & $80 \mathrm{~S}$ & $80 \mathrm{~S}$ & $15 \mathrm{MR} / \mathrm{MS}$ \\
\hline Pc 48 & $\mathrm{~S}$ & $\mathrm{~S}$ & $80 \mathrm{~S}$ & $80 \mathrm{~S}$ & $30 \mathrm{~S}$ \\
\hline Pc50 & $\mathrm{S}$ & $\mathrm{S}$ & $50 \mathrm{~S}$ & $60 \mathrm{~S}$ & $3 \mathrm{~S}$ \\
\hline Pc51 & $\mathrm{S}$ & $\mathrm{S}$ & $80 \mathrm{~S}$ & $80 \mathrm{~S}$ & $10 \mathrm{~S}$ \\
\hline Pc52 & $\mathrm{S}$ & $\mathrm{S}$ & $60 \mathrm{~S}$ & $50 \mathrm{~S}$ & $20 \mathrm{~S}$ \\
\hline Pc53 & $\mathrm{R}$ & MS & TraceS & TraceS & TraceR/MR \\
\hline Pc54 & MS & MS & $80 \mathrm{~S}$ & $25 \mathrm{~S}$ & $10 \mathrm{~S}$ \\
\hline Pc55 & $\mathrm{S}$ & $\mathrm{S}$ & $80 \mathrm{~S}$ & $80 \mathrm{~S}$ & $15 \mathrm{~S}$ \\
\hline Pc56 & $\mathrm{S}$ & $\mathrm{S}$ & $80 \mathrm{~S}$ & $80 \mathrm{~S}$ & $20 \mathrm{~S}$ \\
\hline Pc57 & $\mathrm{S}$ & $\mathrm{S}$ & 30MR/MS & $80 \mathrm{~S}$ & $5 \mathrm{~S}$ \\
\hline Pc58 & MR/MS & MR/MS & $80 \mathrm{~S}$ & $20 \mathrm{~S}$ & $5 \mathrm{MS}$ \\
\hline Pc59 & $\mathrm{S}$ & $\mathrm{S}$ & $50 \mathrm{~S}$ & $80 \mathrm{~S}$ & $10 \mathrm{MS} / \mathrm{S}$ \\
\hline Pc60 & $\mathrm{S}$ & MS & $80 \mathrm{~S}$ & $60 \mathrm{~S}$ & $10 \mathrm{~S}$ \\
\hline Pc61 & MS & $\mathrm{S}$ & $30 \mathrm{~S}$ & $80 \mathrm{~S}$ & $20 \mathrm{~S}$ \\
\hline Pc62 & MS & $\mathrm{S}$ & $30 \mathrm{~S}$ & $5 \mathrm{~S}$ & $3 \mathrm{~S}$ \\
\hline Pc63 & $\mathrm{S}$ & $\mathrm{S}$ & $40 \mathrm{~S}$ & $80 \mathrm{~S}$ & 3MS/MR \\
\hline Pc64 & $\mathrm{S}$ & $\mathrm{S}$ & $60 \mathrm{~S}$ & $10 \mathrm{~S}$ & $5 \mathrm{~S}$ \\
\hline Pc67 & MR & MS & $30 \mathrm{MS} / \mathrm{S}$ & $60 \mathrm{~S}$ & $25 \mathrm{~S}$ \\
\hline Рc68 & $\mathrm{S}$ & $\mathrm{S}$ & $30 \mathrm{~S}$ & $40 \mathrm{~S}$ & $10 \mathrm{~S}$ \\
\hline Pc70 & $\mathrm{S}$ & $\mathrm{S}$ & $40 \mathrm{~S}$ & $80 \mathrm{~S}$ & $10 \mathrm{~S}$ \\
\hline$P c 71$ & $\mathrm{~S}$ & $\mathrm{~S}$ & $80 \mathrm{~S}$ & $80 \mathrm{~S}$ & Dead \\
\hline Pc 91 & $\mathrm{~S}$ & $\mathrm{~S}$ & $5 \mathrm{MS} / \mathrm{S}$ & $1 \mathrm{~S}$ & $1 \mathrm{~S}$ \\
\hline Pc 94 & HR & $S$ & 0 & TraceS & 0 \\
\hline Pc96 & $\mathrm{S}$ & $\mathrm{S}$ & $5 \mathrm{~S}$ & $10 \mathrm{~S}$ & 0 \\
\hline $\mathrm{IAB} 05 \mathrm{Xsel}^{\mathrm{c}}$ & $\mathrm{S}$ & $\mathrm{S}$ & $5 \mathrm{~S}$ & $80 \mathrm{~S}$ & $10 \mathrm{~S}$ \\
\hline WIX4361-9 & $\mathrm{S}$ & $\mathrm{S}$ & $20 \mathrm{~S}$ & $80 \mathrm{~S}$ & $1 \mathrm{MS}$ \\
\hline TAM-O-405 & $\mathrm{S}$ & $\mathrm{S}$ & $10 \mathrm{~S}$ & $3 \mathrm{~S}$ & $1 \mathrm{~S}$ \\
\hline
\end{tabular}

${ }^{a}$ Reaction phenotypes are $\mathrm{HR}=$ no visible reaction, $\mathrm{R}=$ chlorotic or necrotic flecking, $\mathrm{MR}=$ small pustule surrounded by chlorosis, MS = moderately large pustules surrounded by extensive chlorosis, and $\mathrm{S}=$ large to moderately large pustules with little or no chlorosis; Dead = plants died prematurely due to severe crown rust infection. When more than one reaction type is listed, the most frequent reaction type is listed first.

${ }^{\mathrm{b}}$ Pc58 in the differential TAM-O-301 has recently been shown to be a complex of three linked loci (7).

c IAB605X, WIX4361-9, and TAM-O-405 are widely used sources of crown resistance that have not been genetically characterized. scribed above for the test with race DBBC. Seedlings of accessions that were scored moderately resistant or better were transplanted into a pasteurized soil mix in 12.5$\mathrm{cm}$-diameter plastic pots and grown on until they reached the stem elongation growth stage (Feekes 7 to 8 ) and were reinoculated with the 2007 buckthorn bulk population of $P$. coronata $\mathrm{f}$. sp. avenae. In instances where the accession appeared to be heterogeneous in reaction, seedlings that were moderately resistant or better were chosen to be grown on and tested with the 2007 buckthorn bulk as adult plants. A few susceptible seedlings from heterogeneous accessions were also grown on and tested to confirm their susceptibility.

\section{RESULTS}

Of the 402 accessions of A. barbata received from the National Small Grains Germplasm Collection and planted, 359 actually germinated and were evaluated for crown rust resistance. When tested as seedlings with race $\mathrm{DBBC}$ of $P$. coronata, 140 accessions $(39 \%)$ were rated at least moderately resistant. Of these, 48 were rated at least moderately resistant when tested as seedlings with bulk inocula from the 2006 and 2007 St. Paul buckthorn nursery (Table 2). Of the 48 accessions, 3 (PI320630, PI320727, and PI337737) were rated as moderately susceptible when evaluated as adult plants with bulk inoculum from the 2007 St. Paul buckthorn nursery.

Resistance reactions among the remaining 45 accessions ranged from moderately resistant to highly resistant (Table 2). Two accessions, PI320588 from Israel and PI337893 from Italy, were consistently highly resistant (no visible reaction) to all inocula used in the tests. Two other accessions, PI337886 from Italy and PI367293 from Spain, consistently produced resistant reactions (chlorotic flecks) to all inocula. With the remaining accessions, resistance reactions varied somewhat depending on the inoculum used or plant stage they were inoculated. Several accessions were clearly heterogeneous in reaction, either containing a mixture of both susceptible and resistant reactions or a mixture of resistant reaction types. When samples of resistant and susceptible seedlings from heterogeneous accessions were transplanted separately, grown on, and tested as adult plants with bulk inoculum from the 2007 St. Paul buckthorn nursery, they maintained their seedling reaction types, verifying their heterogeneity.

Broad-spectrum resistance (having at least a moderate resistant reaction to all inocula used) to $P$. coronata was found in accessions of $A$. barbata from a diversity of origins in its native range, including Israel, Italy, Greece, France (Corsica), Tunisia, Morocco, Algeria, Libya, Spain, Portugal, and Turkey (Fig. 1), as well as in three accessions from Canada, where it is 
an introduced species. No broad-spectrum resistance was found in accessions from Serbia, Bulgaria, the United Kingdom, Pakistan, India, Iran, Cyprus, Jordan, Egypt, Macedonia, or Brazil. These countries were only represented by one or two accessions of $A$. barbata each in the USDA germplasm collection.

\section{DISCUSSION}

The relatively high frequency of resistance (approximately 13\%) in A. barbata to the highly diverse, widely virulent population of $P$. coronata in the St. Paul buckthorn nursery is surprising and encouraging. Every year, hundreds of oat lines from breeding programs across the United States and Canada, oat germplasm accessions, recombinant inbred and breeding populations of domesticated oat, selections of A. strigosa and A. murphyii, and oat lines with resistance genes introgressed from those wild relatives are evaluated for crown rust resistance in the buckthorn nursery in St. Paul. The only A. sativa cultivar or line that is totally resistant in the buckthorn nursery is AC Leggett (a combination of Pc68 and Pc94). The only other Avena spp. completely resistant to the buckthorn population are a single accession of the diploid A. strigosa (PI258731) and a selection of the tetraploid A. murphyii (P12). It appears that $A$. barbata represents a previously untapped reservoir of new crown rust resistance genes for improvement of oat cultivars.

It is also likely that the resistance found in these accessions of A. barbata is diverse. First, their reaction to the bulk populations from the buckthorn nursery, ranging from highly to moderately resistant, is indicative of different resistance genes being expressed. Second, the resistant accessions come from geographically diverse regions from across the native range of A. barbata (Fig. 1) but also from an introduced population outside its native distribution. Thus, A. barbata appears to be a source of diverse and novel genes for resistance to a broad spectrum of virulence in $P$. coronata in the United States.

Many of the accessions of $A$. barbata exhibiting wide-spectrum resistance to $P$. coronata were from Israel (Table 1). Although it would be tempting to state that Israel is a particularly rich source of resistant accessions of $A$. barbata, this is more a reflection of the large number of accessions (165) from Israel in the collection. When the frequency of accessions with broad-spectrum resistance from different countries in the Mediterranean region is examined, Italy and Corsica appear to be richer sources of resistant accessions than Israel (Fig. 1). Given the relatively high frequency (approximately 13\%) of accessions from throughout the natural range of A. barbata with effective resistance to crown rust, it would be desirable to make further collections from those areas that are underrepresented in the USDA germplasm collection.

Introgression of the resistance of the tetraploid A. barbata into hexaploid oat will be difficult. Sterility and the lack of homology between chromosomes between A. barbata and A. sativa represent significant barriers. Resistance to powdery mildew was successfully transferred from $A$. barbata to cultivated oat using two different approaches. First, a chromosomal addition line of $A$. sativa $(42+2$ chromosomes) with the A. barbata chromosome carrying the resistance gene was irradiated to induce a translocation between an $A$. sativa chromosome and the A. barbata chromosome, followed by selection in subsequent generations for resistant plants in families that segregated normally for resistance and susceptibility (1). The second method involved crossing a ditelocentric addition line of A. sativa cv. Sun II (42 A. sativa chromosomes plus a pair of telocentrics for the short arm of an A. barbata chromosome) with an $8 \mathrm{x}$ amphiploid between $A$. sativa cv. Pendek and $A$. longiglumis CW57 (16). CW57 carries a factor allowing recombination between

Table 2. Reactions of selected accessions of Avena barbata to race DBBC and bulk populations of Puccinia coronata from the St. Paul buckthorn nursery ${ }^{\mathrm{a}}$

\begin{tabular}{|c|c|c|c|c|c|}
\hline \multirow[b]{2}{*}{ Accession } & \multirow[b]{2}{*}{ Origin } & \multicolumn{3}{|c|}{ Seedling ${ }^{b}$} & \multirow{2}{*}{$\begin{array}{r}\text { Adult } \\
\text { 07Bulk }\end{array}$} \\
\hline & & DBBC & 06Bulk & 07Bulk & \\
\hline CIav8082 & Israel & $\mathrm{R}$ & $\mathrm{R}$ & $\mathrm{MR} / \mathrm{R}$ & $\mathrm{HR} / \mathrm{R}$ \\
\hline CIav9060 & Canada & HR & $\mathrm{R}$ & $\mathrm{HR} / \mathrm{S}$ & HR \\
\hline CIav9067 & Canada & MR & MR/MS & MR/MS/S & - \\
\hline CIav9091 & Libya & $\mathrm{R}$ & $\mathrm{R}$ & HR & MR \\
\hline CIav9125 & Canada & $\mathrm{R}$ & MR & MR & - \\
\hline PI282710 & Israel & $\mathrm{R}$ & HR & $\mathrm{R}$ & $\mathrm{HR} / \mathrm{R}$ \\
\hline PI282723 & Israel & $\mathrm{R}$ & $\mathrm{R} / \mathrm{S}$ & HR & $\mathrm{R} / \mathrm{MR} / \mathrm{HR}$ \\
\hline PI287203 & Israel & $\mathrm{R}$ & $\mathrm{R}$ & HR & $\mathrm{HR} / \mathrm{R}$ \\
\hline PI287205 & Israel & MR & MR & $\mathrm{S} / \mathrm{R}$ & MS/MR \\
\hline PI295885 & Israel & $\mathrm{R}$ & $\mathrm{R}$ & $\mathrm{HR} / \mathrm{S}$ & HR \\
\hline PI295891 & Israel & HR & $\mathrm{R}$ & $\mathrm{R} / \mathrm{MR}$ & HR/R \\
\hline PI317945 & Israel & HR & HR & HR & HR/R \\
\hline PI317953 & Israel & HR & HR & $\mathrm{R} / \mathrm{MR}$ & HR \\
\hline PI320588 & Israel & HR & HR & HR & HR \\
\hline PI320598 & Israel & MS & $\mathrm{R}$ & MS/MR & MR/MS \\
\hline PI320610 & Israel & $\mathrm{R} / \mathrm{MR}$ & $\mathrm{R}$ & $\mathrm{MR} / \mathrm{R}$ & $\mathrm{MR} / \mathrm{R}$ \\
\hline PI320630 & Israel & MR & - & HR & MS \\
\hline PI320638 & Israel & $\mathrm{R}$ & $\mathrm{R} / \mathrm{S}$ & MR & MR \\
\hline PI320659 & Israel & $\mathrm{R}$ & MR & MS/MR & MR \\
\hline PI320696 & Israel & MR/MS & MR & HR/R & $\mathrm{R}$ \\
\hline PI320727 & Israel & MR & - & $\mathrm{S} / \mathrm{R}$ & MS \\
\hline PI337737 & Italy & $\mathrm{R} / \mathrm{MR}$ & $\mathrm{MR} / \mathrm{R}$ & MS/MR & MS \\
\hline PI337741 & Italy & MR & $\mathrm{R} / \mathrm{MR}$ & MR & $\mathrm{R}$ \\
\hline PI337744 & Italy & MR & MS/MR & MR & $\mathrm{R}$ \\
\hline PI337763 & France & $\mathrm{R}$ & R/MR & $\mathrm{MR} / \mathrm{R} / \mathrm{S}$ & $\mathrm{MR} / \mathrm{R}$ \\
\hline PI337795 & Morocco & $\mathrm{R}$ & $\mathrm{R}$ & HR & $\mathrm{R}$ \\
\hline PI337811 & Turkey & MR & MR/MS & MR/MS & MR \\
\hline PI337823 & Greece & $\mathrm{R}$ & $\mathrm{R}$ & $\mathrm{MR} / \mathrm{R}$ & MR \\
\hline PI337863 & Italy & $\mathrm{R}$ & MR & MS/MR & MR \\
\hline PI337864 & Italy & $\mathrm{R}$ & R/MR & R/MR & $\mathrm{MR} / \mathrm{R}$ \\
\hline PI337867 & Italy & HR & MR & $\mathrm{HR} / \mathrm{R} / \mathrm{MR}$ & HR/R/MR \\
\hline PI337868 & Italy & $\mathrm{R}$ & R/MR & MR & MR \\
\hline PI337877 & Italy & $\mathrm{R}$ & MR & MR & MR/R \\
\hline PI337878 & Italy & $\mathrm{R}$ & MR & $\mathrm{MR} / \mathrm{R}$ & $\mathrm{R}$ \\
\hline PI337886 & Italy & $\mathrm{R}$ & $\mathrm{R}$ & $\mathrm{R}$ & $\mathrm{R}$ \\
\hline PI337893 & Italy & HR & HR & HR & HR \\
\hline PI337904 & Italy & MR & $\mathrm{R}$ & MS/MR & MR \\
\hline PI337945 & Tunisia & R/MR & R/MR & MR & MR \\
\hline PI337961 & Italy & $\mathrm{R}$ & $\mathrm{MR} / \mathrm{S}$ & MR/MS & MR \\
\hline PI337962 & Italy & R/MR & MR/MS & $\mathrm{MR} / \mathrm{R}$ & $\mathrm{MR} / \mathrm{R}$ \\
\hline PI337966 & France & $\mathrm{R}$ & $\mathrm{R} / \mathrm{MR} / \mathrm{S}$ & $\mathrm{MR} / \mathrm{R} / \mathrm{MS}$ & $\mathrm{MR} / \mathrm{R}$ \\
\hline PI337975 & Algeria & $\mathrm{R}$ & $\mathrm{R} / \mathrm{MS}$ & MR & MR \\
\hline PI367293 & Spain & $\mathrm{R}$ & $\mathrm{R}$ & $\mathrm{R}$ & $\mathrm{R}$ \\
\hline PI367296 & Spain & $\mathrm{R}$ & $\mathrm{R}$ & $\mathrm{MR} / \mathrm{R}$ & $\mathrm{R}$ \\
\hline PI367318 & Portugal & $\mathrm{R}$ & $\mathrm{R}$ & $\mathrm{R}$ & HR \\
\hline PI367319 & Portugal & $\mathrm{R}$ & $\mathrm{R}$ & MR & HR/R \\
\hline PI367338 & Portugal & $\mathrm{S}$ & MR & $\mathrm{R} / \mathrm{MR}$ & $\mathrm{R} / \mathrm{MR}$ \\
\hline PI411376 & Turkey & $\mathrm{R}$ & $\mathrm{R}$ & $\mathrm{MR} / \mathrm{R}$ & $\mathrm{R} / \mathrm{MR}$ \\
\hline
\end{tabular}

${ }^{a}$ Reaction phenotypes are $\mathrm{HR}=$ no visible reaction, $\mathrm{R}=$ chlorotic or necrotic flecking, $\mathrm{MR}=$ small pustule surrounded by chlorosis, MS = moderately large pustules surrounded by extensive chlorosis, and $\mathrm{S}=$ large to moderately large pustules with little or no chlorosis $-=$ accession not tested. When more than one reaction type is listed, this indicates that the accession was apparently heterogeneous. The more frequent reaction type is listed first.

b 06Bulk and 07Bulk populations represent random samples of urediniospores collected from the St. Paul buckthorn nursery in 2006 and 2007, respectively. 


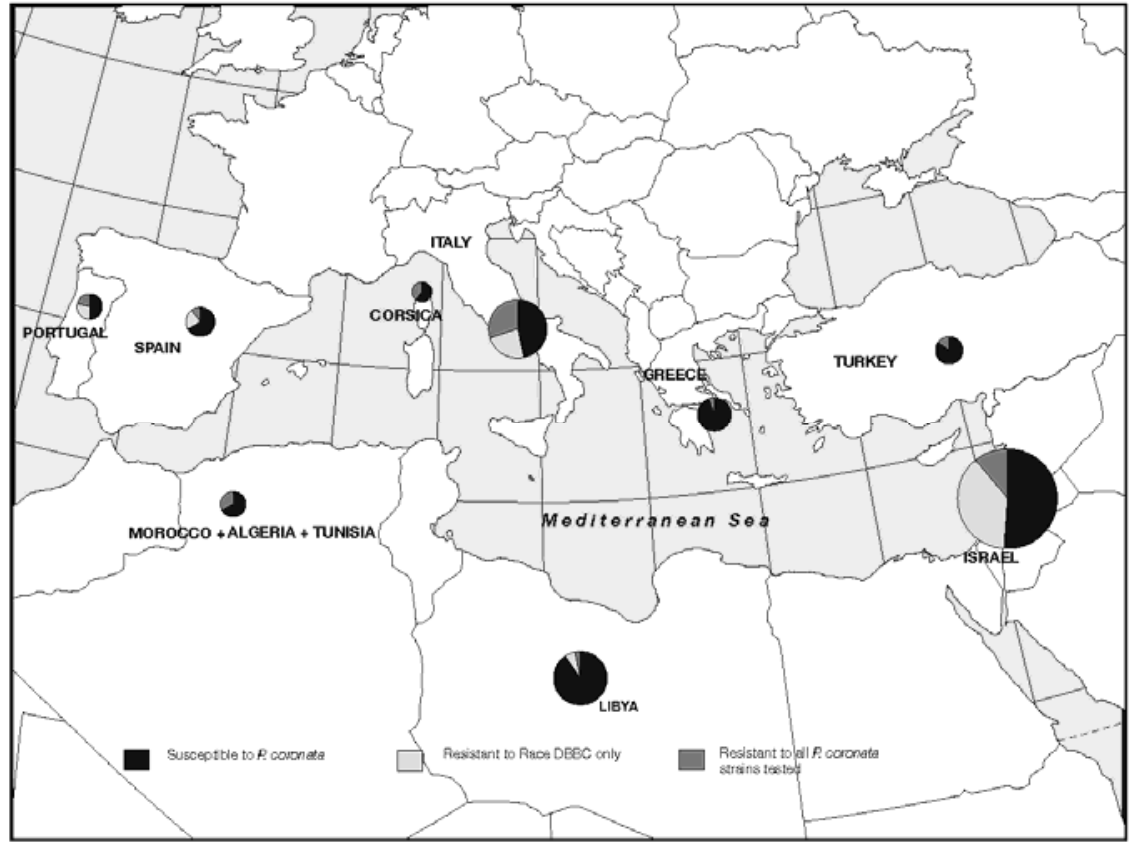

Fig. 1. Distribution of Avena barbata accessions with broad-spectrum resistance to Puccinia coronata in the world.

homologous chromosomes similar to what occurs when the $P h-1$ locus in wheat is suppressed or deleted. This initial cross was followed by selection in subsequent generations for fertile, resistant plants with 42 chromosomes. The stem rust resistance gene Pgl6 was also successfully transferred to A. sativa from $A$. barbata by backcrossing to $A$. sativa for several generations, selecting for resistance, followed by irradiation to facilitate chromosomal recombination followed by selection for resistance (10).

Initial crosses of some of the selected resistant accessions of $A$. barbata have been made with oat cvs. Otana and Ogle. Crossing was successful only when $A$. barbata was used as the female parent. A sampling of $F_{1}$ seedlings expressed resistance when inoculated with a bulk inoculum of $P$. coronata, indicating that resistance is not suppressed in interspecific crosses with $A$. barbata as has been reported in crosses of $A$. strigosa and $A$. murphyii with A. sativa (13).

Although A. barbata appears to be a promising source of new, broad-spectrum crown rust resistance in oat, there is no reason to expect that this resistance will be any more durable than seedling resistance derived from other wild Avena spp. such as A. sterilis or A. strigosa if not used wisely. However, it is likely that the A. barbata germplasm pool contains a diversity of resistance genes. This raises the possibility of extending the useful life of this resistance by increasing the diversity of highly resistant cultivars deployed in a given region by using different resistant genes from $A$. barbata in different cultivars, rather than breeding programs relying on a single new effective resistance gene in all new cultivars. This would reduce the likelihood of a new race or races virulent on any one of these new resistance genes predominating in the $P$. coronata population and causing widespread damage. Different effective resistance genes from $A$. barbata could also be pyramided into cultivars, theoretically increasing their effective lifespan.

\section{LITERATURE CITED}

1. Aung, T., Thomas, H., and Jones, I. T. 1977. The transfer of the gene for mildew resistance from Avena barbata (4x) into the cultivated oat A. sativa by an induced translocation. Euphytica 26:623-632.

2. Aung, T., Chong, J., and Leggett, M. 1996.
The transfer of crown rust resistance $P c 94$ from a wild diploid to cultivated hexaploid oat. Pages 167-171 in: Proc. 9th Int. Eur. Mediterr. Cereal Rusts and Powdery Mildews Conf. Lunteren, The Netherlands. G. H. J. Kema, R. E. Niks, and R. A. Daamen, eds. European and Mediterranean Cereal Rust Foundation, Wageningen, The Netherlands.

3. Carson, M. L. 2008. Virulence frequencies in oat crown rust in the United States from 2001 through 2005. Plant Dis. 92:379-384.

4. Chong, J., Leonard, K. J., and Salmeron, J. J. 2000. A North American system of nomenclature for Puccinia coronata f. sp. avenae. Plant Dis. 84:580-585.

5. Dinoor, A. 1970. Sources of oat crown rust resistance in hexaploid and tetraploid wild oats in Israel. Can. J. Bot. 48:153-161.

6. Dinoor, A., and Wahl, I. 1963. Reaction of non-cultivated oats from Israel to Canadian races of crown rust and stem rust. Can. J. Plant Sci. 43:263-270.

7. Hoffman, D. L., Chong, J., Jackson, E. W., and Obert, D. E. 2006. Characterization and mapping of a crown rust gene complex (Pc58) in TAM O-301. Crop Sci. 46:2630-2635.

8. Karow, R. S., McNamara, K. R., and Forsberg, R. A. 1987. Crown rust resistance in progeny from a derived tetraploid $\mathrm{X}$ natural tetraploid cross in Avena. Genome 29:206-208.

9. Leggett, J. M. 1992. Classification and speciation in Avena. Pages 29-52 in: Oat Science and Technology. H. G. Marshall and M. E. Sorrells, eds. American Society of Agronomy, Madison, WI

10. Martens, J. W. 1985. Oat stem rust. Pages 103129 in: The Cereal Rusts: Vol. II. Diseases, Distribution, Epidemiology, and Control. A. P. Roelfs and W. R. Bushnell, eds. Academic Press, Orlando, FL.

11. Martens, J. W., McKenzie, R. I. H., and Harder, D. E. 1980. Resistance to Puccinia graminis avenae and $P$. coronata avenae in the wild and cultivated Avena populations of Iran, Iraq, and Turkey. Can. J. Genet. Cytol. 22:641-649.

12. McMullen, M. S., Doehlert, D. C., and Miller, J. D. 2005. Registration of 'HiFi' oat. Crop Sci. 45:1664.

13. Rines, H. W., Porter, H. L., Carson, M. L., and Ochocki, G. E. 2007. Introgression of crown rust resistance from diploid oat Avena strigosa into hexaploid cultivated oat $A$. sativa by two methods: direct crosses and through an initial $2 \mathrm{x}-4 \mathrm{x}$ synthetic hexaploid. Euphytica 158:67-79.

14. Sadanaga, K., and Simon, M. D. 1960. Transfer of crown rust resistance of diploid and tetraploid species to hexaploid oats. Agron. J. 52:285-288.

15. Simons, M. D. 1985. Crown rust. Pages 131172 in: The Cereal Rusts: Vol. II. Diseases, Distribution, Epidemiology, and Control. A. P. Roelfs and W. R. Bushnell, eds. Academic Press, Orlando, FL.

16. Thomas, H., Powell, W., and Aung, T. 1980. Interfering with regular meiotic behavior in Avena sativa as a method of incorporating the gene for mildew resistance from A. barbata. Euphytica 29:635-640. 